\title{
Temperature and exposure time-dependent scintillation of Eu(III) polyoxometalate under X-ray excitation
}

\author{
Higor Henrique de Souza Oliveira ${ }^{\mathrm{a}, \mathrm{b}, *}$, Marco Aurélio Cebim ${ }^{\mathrm{a}}$, Marian Rosaly Davolos ${ }^{\mathrm{a}}$ \\ a Universidade Estadual Paulista (Unesp), Instituto de Química, Araraquara, SP, Brazil \\ ${ }^{\mathrm{b}}$ Instituto Federal de Educação, Ciência e Tecnologia de São Paulo (IFSP), Matão, SP, Brazil
}

\section{A R T I C L E I N F O}

\section{Keywords:}

Europium

Polyoxometalate

Scintillation

XEOL

\begin{abstract}
A B S T R A C T
Sodium decatungstoeuropate, $\mathrm{Na}_{9}\left[\mathrm{Eu}\left(\mathrm{W}_{5} \mathrm{O}_{18}\right)_{2}\right] \cdot 14 \mathrm{H}_{2} \mathrm{O}$, is a promising material to convert X-ray into visible light. In this work, temperature and exposure time-dependent scintillation of the $\mathrm{Na}_{9}\left[\mathrm{Eu}\left(\mathrm{W}_{5} \mathrm{O}_{18}\right)_{2}\right] \cdot 14 \mathrm{H}_{2} \mathrm{O}$ sample under X-ray excitation were evaluated. Light emission intensity decreases along with $\mathrm{X}$-ray exposure time, probably due to electronic defects at $\left(\mathrm{W}_{5} \mathrm{O}_{18}\right)^{6-}$ groups, leading to a lower efficiency of the LMCT $(\mathrm{O} \rightarrow \mathrm{W})$ process, which is determinant in the scintillation mechanism of this material. After X-ray exposition, there is a partial recovery of the initial emission intensity, indicating that defects created are reversible. With temperature increasing, changes in the emission spectra evidence the decreasing of the local symmetry around the Eu ${ }^{3+}$ ions, caused by reticular vibration and dehydration process. The luminescence intensity dependence with temperature suggests the possibility to use this material as molecular thermometer in two different temperatures ranges.
\end{abstract}

\section{Introduction}

Scintillators are materials that can convert ionizing radiations (like $\mathrm{X}$-rays) into visible light [1]. Due to this property, these materials are used in ionizing radiations detection and are applied in high-energy physics, dosimetry and medical imaging technologies [2-4]. Despite of impressive advances in the technology of direct detection, the search for new lanthanide-based scintillators materials with high efficiency and for new conformations of these materials is still the focus of research in this area [5-7].

In this context, lanthanide ions-based compounds are promising scintillator materials, due to the singular luminescent properties of these ions [8]. Polyoxometalates containing lanthanide ions (LnPOM) have electrical, magnetic and optical properties with large technological interest [9-11]. Besides, LnPOM can be prepared from low cost synthetic routes and molded into different conformations [10,12-14].

Among LnPOM materials, sodium decatungstoeuropate, $\mathrm{Na}_{9}[\mathrm{Eu}$ $\left.\left(\mathrm{W}_{5} \mathrm{O}_{18}\right)_{2}\right] \cdot 14 \mathrm{H}_{2} \mathrm{O}$, presents intense red emission with color purity, high luminescence quantum efficiency under ultraviolet (UV) excitation and can be prepared at different conformations [15]. Moreover, europium and tungsten elements have high X-ray mass attenuation coefficients, indicating that this material present high X-ray absorption. The synthesis of this compound dates back almost five decades [16] and since then, there have been no studies about its luminescence under X-ray excitation and about the temperature influence on its luminescent properties.

The study of the luminescent properties as a function of temperature and X-ray exposure time is important to evaluate the possibility of application of the material in scintillation devices. In this work, we discuss the temperature and exposure time-dependent scintillation of the $\mathrm{Na}_{9}\left[\mathrm{Eu}\left(\mathrm{W}_{5} \mathrm{O}_{18}\right)_{2}\right] \cdot 14 \mathrm{H}_{2} \mathrm{O}$ under X-ray excitation.

\section{Experimental}

Sodium decatungstoeuropate, $\mathrm{Na}_{9}\left[\mathrm{Eu}\left(\mathrm{W}_{5} \mathrm{O}_{18}\right)_{2}\right] \cdot 14 \mathrm{H}_{2} \mathrm{O}$, was prepared according to the procedure described in literature [16-18], starting from sodium tungstate and europium chloride $1.25 \mathrm{~mol} \mathrm{~L}^{-1}$ solutions. After pH adjustment, stirring, heating and rest, the obtained solid crystals were filtered, washed, dried and characterized. The number of lattice water molecules was determined by thermogravimetric analysis and it agrees with literature [18].

Temperature and exposure time-dependent scintillation was investigated by X-ray Excited Optical Luminescence (XEOL) measurements performed using a homemade instrumentation [19]. $\mathrm{Na}_{9}[\mathrm{Eu}$ $\left.\left(\mathrm{W}_{5} \mathrm{O}_{18}\right)_{2}\right] \cdot 14 \mathrm{H}_{2} \mathrm{O}$ sample was excited by copper soft X-ray from an $800 \mathrm{~W}(40 \mathrm{kV}$ and $20 \mathrm{~mA}) \mathrm{X}$-ray source and light output collected with an optical fiber (SR-OPT-8050, RoMack Inc., one way fiber bundle, $100 \mu \mathrm{m}$ core, HOH-UV/VIS, 6.0m) coupled to a SHAMROCK 163 spectrometer, Andor Tech., equipped with 600 lines $\mathrm{mm}^{-1}$ diffraction grating and $1024 \times 127$ pixels iDus DV401A-BV CCD camera, Andor

\footnotetext{
* Corresponding author at: Instituto Federal de Educação, Ciência e Tecnologia de São Paulo (IFSP), Matão, SP, Brazil.

E-mail address: higorhsoliveira@ifsp.edu.br (H.H.d.S. Oliveira).
} 
Tech.

To evaluate the X-ray exposure time-dependent scintillation, the luminescent polyoxometalate in the sample holder accessory was excited by continuous $\mathrm{X}$-ray beam and emission spectra were recorded in front face mode each 2 min during the experiment time at room temperature. UV-excited photoluminescence spectroscopy (UV-PLS) measurements were also performed in intervals between the X-ray exposure time experiments. UV-PLS measurements were performed in FLUOROLOG HORIBA JOBIN YVON fluorimeter, FL3-222 model, with Xenon arc lamp as excitation light source.

Temperature-dependent scintillation was evaluated using a cryostat-oven accessory coupled to the X-ray source. This accessory was designed in our lab in collaboration with the Microtube Ferramentaria de Precisão e Comércio LTDA-ME company. In this accessory, the system temperature is lowered with the use of liquid $\mathrm{N}_{2}$, and increased with the use of an electrical resistance. Emission spectra were recorded with the sample holder fixed at $30^{\circ}$ of the X-ray excitation beam in the -100 to $350^{\circ} \mathrm{C}$ temperature range $\left(25^{\circ} \mathrm{C}\right.$ step $)$.

\section{Results and discussion}

\subsection{Exposure time-dependent scintillation}

Fig. 1 shows the emission spectra of the $\mathrm{Na}_{9}\left[\mathrm{Eu}\left(\mathrm{W}_{5} \mathrm{O}_{18}\right)_{2}\right] \cdot 14 \mathrm{H}_{2} \mathrm{O}$ sample recorded at beginning ( $2 \mathrm{~min}$ ) and ending ( $480 \mathrm{~min}$ ) of the X-ray exposure time experiment. The known emission spectral profile of the sodium decatungstoeuropate is observed, with all lines attributed to ${ }^{5} \mathrm{D}_{0} \rightarrow{ }^{7} \mathrm{~F}_{\mathrm{J}}(J=0-4)$ transitions of the Eu ${ }^{3+}$ ion and with ${ }^{5} \mathrm{D}_{0} \rightarrow{ }^{7} \mathrm{~F}_{1}$ lines more intense than ${ }^{5} \mathrm{D}_{0} \rightarrow{ }^{7} \mathrm{~F}_{2}$ lines due to $\mathrm{Eu}^{3+}$ high symmetry site $\left(\mathrm{D}_{4 \mathrm{~d}}\right)$ $[17,18]$. After $480 \mathrm{~min}$ under X-ray exposure, emission intensity is reduced to approximately $65 \%$ of the initial intensity. However, there are no changes in the emission spectral profile. $\mathrm{Eu}^{3+}$ ion is a known spectroscopic probe, because its emission spectral profile is influenced by the local chemical environment. Then, despite of the emission intensity decreasing, there are not evidences of local structural changes in the $\mathrm{Eu}^{3+}$ environment.

Emission intensity of the polyoxometalate (integrated intensity of ${ }^{5} \mathrm{D}_{0} \rightarrow{ }^{7} \mathrm{~F}_{1}$ lines) as a function of the $\mathrm{X}$-ray exposure time can be observed in Fig. 2. It is possible to see that emission intensity decreases under Xray exposure, probably due to electronic defects created by ionizing radiation excitation. This decreasing is more pronounced in the first instants of X-ray excitation and the emission intensity to time ratio becomes smaller and constant along the exposure time. Furthermore, after a period without X-ray exposure $(12 \mathrm{~h})$, it is observed that the emission intensity increases, tending to return to its initial value,

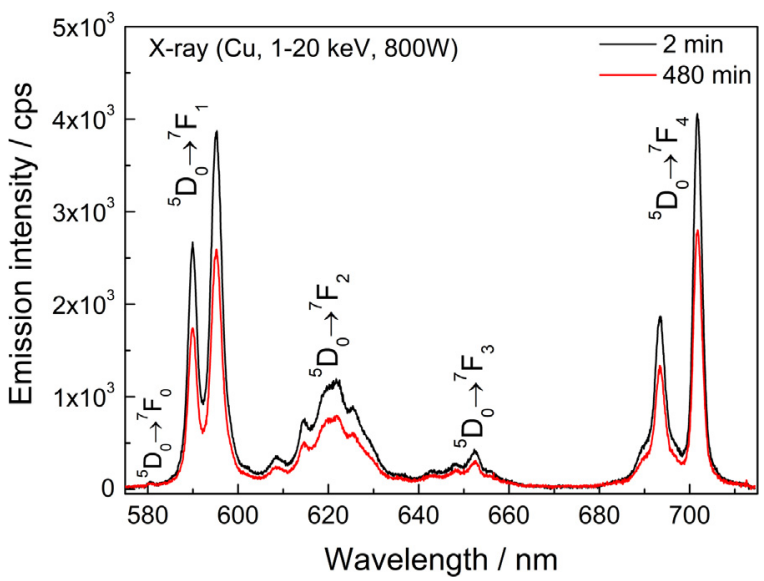

Fig. 1. X-ray excited luminescence spectra of the $\mathrm{Na}_{9}\left[\mathrm{Eu}\left(\mathrm{W}_{5} \mathrm{O}_{18}\right)_{2}\right] \cdot 14 \mathrm{H}_{2} \mathrm{O}$ sample recorded at beginning $(2 \mathrm{~min})$ and ending $(480 \mathrm{~min})$ of the $\mathrm{X}$-ray exposure time experiment.

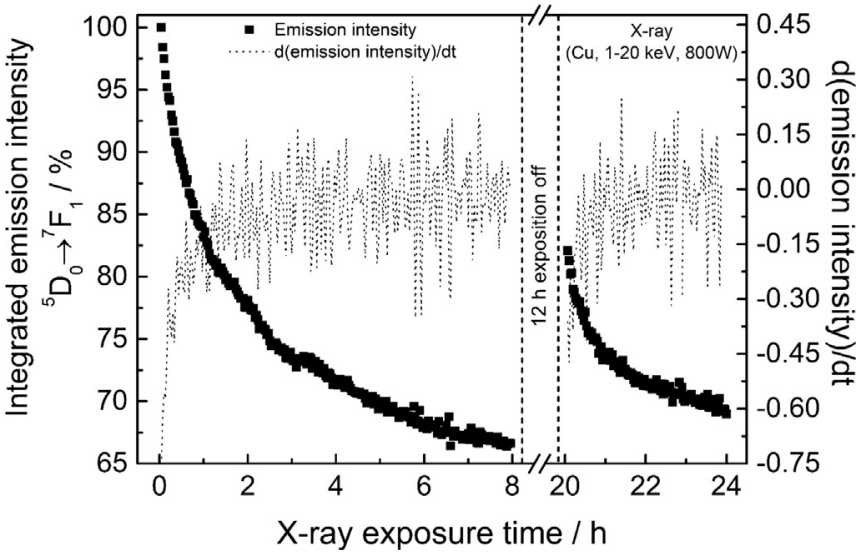

Fig. 2. X-ray excited luminescence intensity of the $\mathrm{Na}_{9}\left[\mathrm{Eu}\left(\mathrm{W}_{5} \mathrm{O}_{18}\right)_{2}\right] \cdot 14 \mathrm{H}_{2} \mathrm{O}$ sample (given by area under the line assigned to the ${ }^{5} \mathrm{D}_{0} \rightarrow^{7} \mathrm{~F}_{1}$ transition) as a function of the X-ray exposure time in a $24 \mathrm{~h}$ experiment: $8 \mathrm{~h}$ under X-ray on, $12 \mathrm{~h}$ under X-ray off and $4 \mathrm{~h}$ under X-ray on.

indicating that the electronic defects created are reversible.

To better understand the scintillation mechanism in this material, emission intensity under X-ray and UV excitation was monitored alternately by XEOL and UV-PLS measurements. The result of this experiment is shown in Fig. 3a. As discussed earlier, the X-ray excitation generates electronic defects in the material. Although it is a reversible process, the restitution of these defects is not immediate, and the emission intensity does not assume its initial value even after a period of time without X-ray exposure. UV-PLS measurements performed between cycles of X-ray exposure shows that emission intensity under UV excitation also is smaller after X-ray exposure, probably because the electronic defects created by the ionizing radiation remains in the material and act as traps, promoting the nonradiative decay. Besides, this experiment reveals that emission from ligand to metal charge transfer (LMCT) excitation mechanism $(275 \mathrm{~nm})$ is more adversely affected by X-ray exposure than emission from $4 f-4 f$ intraconfigurational transition excitation mechanism $(394 \mathrm{~nm}) . \mathrm{W}^{6+}$ ions have a high atomic number and a significative contribution to X-ray mass attenuation coefficients of the sodium decatungstoeuropate. Thus, X-ray absorption is higher in $\left(\mathrm{W}_{5} \mathrm{O}_{18}\right)^{6-}$ groups of the $\left[\mathrm{Eu}\left(\mathrm{W}_{5} \mathrm{O}_{18}\right)_{2}\right]^{9-}$ anion and electronic defects are created predominantly in these groups. The creation of defects levels close to the $\mathrm{Eu}^{3+}$ high energy levels can decrease the energy transfer process efficiency (Fig. 3b), leading to lower $\mathrm{Eu}^{3+}$ excitation by this mechanism. Consequently, the ${ }^{5} \mathrm{D}_{0} \rightarrow{ }^{7} \mathrm{~F}_{1}$ emission intensity of $\mathrm{Eu}^{3+}$ decreases under LMCT states excitation. This analysis suggests that LMCT states are an important part of the scintillation mechanism in this material.

\subsection{Temperature-dependent scintillation}

Fig. 4 shows the emission spectra of the $\mathrm{Na}_{9}\left[\mathrm{Eu}\left(\mathrm{W}_{5} \mathrm{O}_{18}\right)_{2}\right] \cdot 14 \mathrm{H}_{2} \mathrm{O}$ sample recorded at different temperatures, normalized by intensity of the ${ }^{5} \mathrm{D}_{0} \rightarrow{ }^{7} \mathrm{~F}_{1}$ line. When the temperature increases, the ${ }^{5} \mathrm{D}_{0} \rightarrow{ }^{7} \mathrm{~F}_{\mathrm{J}}$ lines becomes broader due to the higher electronic-vibrational coupling. It was observed that the intensity of the ${ }^{5} \mathrm{D}_{0} \rightarrow^{7} \mathrm{~F}_{2}$ line increases in relation to the ${ }^{5} \mathrm{D}_{0} \rightarrow{ }^{7} \mathrm{~F}_{1}$ line due to symmetry changes around the $\mathrm{Eu}^{3+}$ ions. The ${ }^{5} \mathrm{D}_{0} \rightarrow{ }^{7} \mathrm{~F}_{2}$ transition is forbidden at $\mathrm{D}_{4 \mathrm{~d}}$ symmetry, however, it appears in all spectra due to distortions of this symmetry. With the temperature increasing and consequently, with the reticular vibration increasing, probably the $\mathrm{D}_{4 \mathrm{~d}}$ sites are more distorted, decreasing the local symmetry around $\mathrm{Eu}^{3+}$ ions and increasing the intensity of the line assigned to ${ }^{5} \mathrm{D}_{0} \rightarrow{ }^{7} \mathrm{~F}_{2}$ transition. In addition to the vibrational effect, there are water molecules leaving the solid structure at temperatures above $100{ }^{\circ} \mathrm{C}$ and this dehydration process also contributes to modify the structure of the solid and consequently, the local symmetry around 


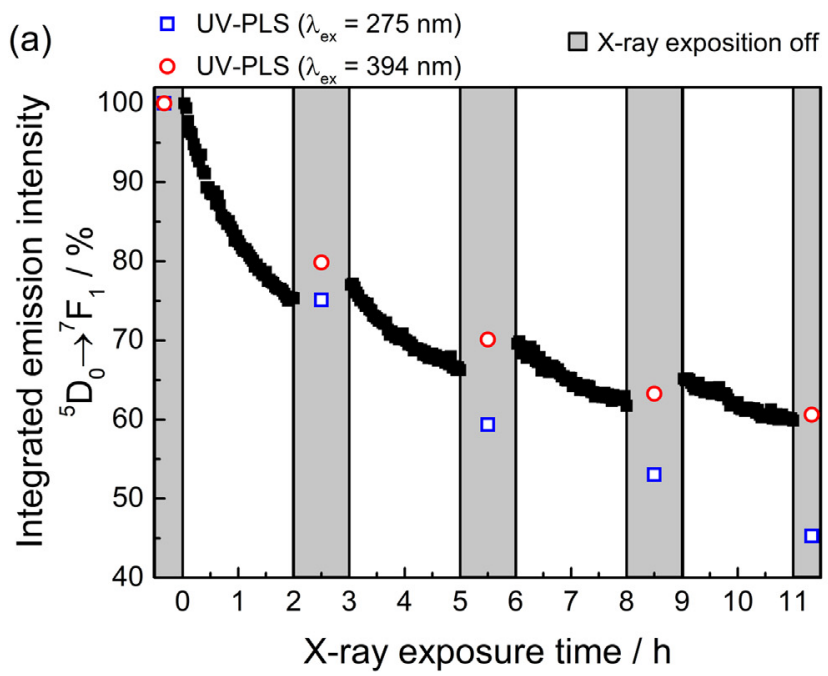

(b)

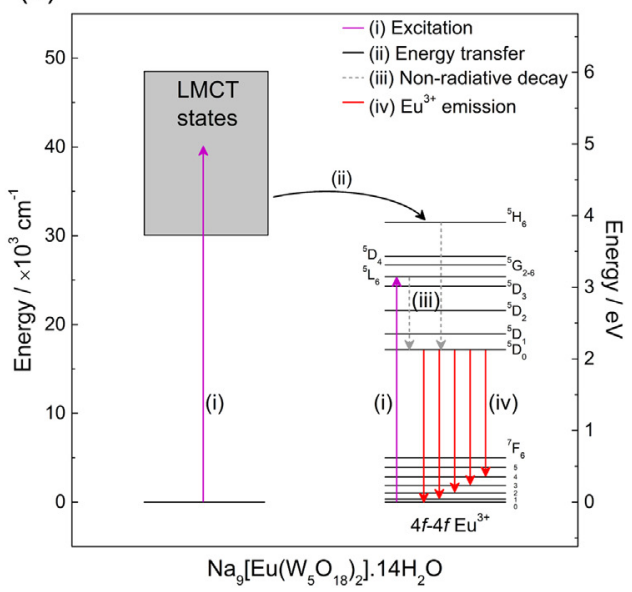

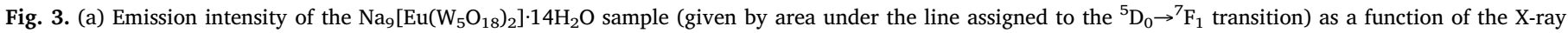

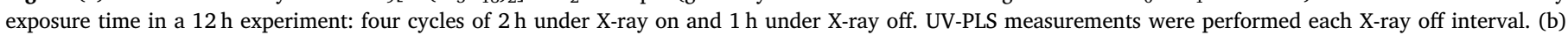
Schematic energy level diagram of the $\mathrm{Na}_{9}\left[\mathrm{Eu}\left(\mathrm{W}_{5} \mathrm{O}_{18}\right)_{2}\right] \cdot 14 \mathrm{H}_{2} \mathrm{O}$.

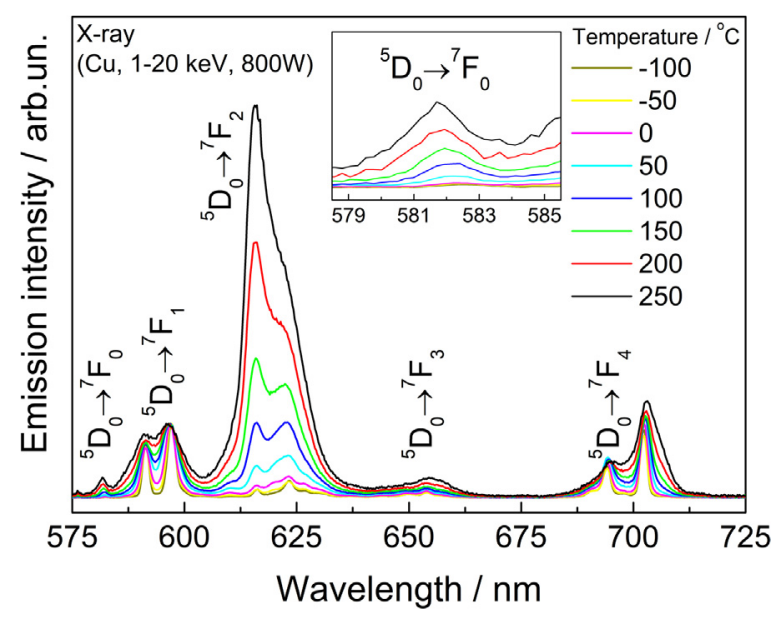

Fig. 4. X-ray excited luminescence spectra of the $\mathrm{Na}_{9}\left[\mathrm{Eu}\left(\mathrm{W}_{5} \mathrm{O}_{18}\right)_{2}\right] \cdot 14 \mathrm{H}_{2} \mathrm{O}$ sample recorded at different temperatures, normalized by intensity of the ${ }^{5} \mathrm{D}_{0} \rightarrow{ }^{7} \mathrm{~F}_{1}$ line.

$\mathrm{Eu}^{3+}$ ions. It is also observed that the intensity of the line assigned to the ${ }^{5} \mathrm{D}_{0} \rightarrow{ }^{7} \mathrm{~F}_{0}$ transition increases due to the $\mathrm{J}$-mixing effect in lower symmetries [20].

Symmetry changes can also be discussed by the analysis of $R_{21}$ parameter, given by the ratio between the integrated area under lines assigned to ${ }^{5} \mathrm{D}_{0} \rightarrow{ }^{7} \mathrm{~F}_{2}$ and ${ }^{5} \mathrm{D}_{0} \rightarrow{ }^{7} \mathrm{~F}_{1}$ transitions. Fig. 5 exhibits the variation of the $R_{21}$ parameter as a function of the temperature. As previously discussed, with temperature increasing, the structural distortions caused by reticular vibration and dehydration process lead to decreasing of the local symmetry around the $\mathrm{Eu}^{3+}$ ions. As consequence, $R_{21}$ parameter increases with the temperature, especially above $100{ }^{\circ} \mathrm{C}$, because dehydration process starts at this temperature and contributes significantly to structural distortions. Comparing X-ray and LMCT (275 nm) excitations, it is possible to see that $R_{21}$ parameter variation is similar for both, indicating that $\mathrm{Eu}^{3+}$ deactivation mechanisms are analogous. These results corroborate the statement that LMCT states are important on the scintillation mechanism of this material. It is also important to note that, to a first approximation, $R_{21}$ parameter increases linearly $\left(R^{2} \sim 0.99\right)$ in two temperature ranges: -100 to $0{ }^{\circ} \mathrm{C}$ and 50 to $250{ }^{\circ} \mathrm{C}$, independent of the excitation energy (Xray or UV). This property allows the use of this material as molecular thermometer in these ranges $[21,22]$. Above $250^{\circ} \mathrm{C}, \mathrm{R}_{21}$ parameter

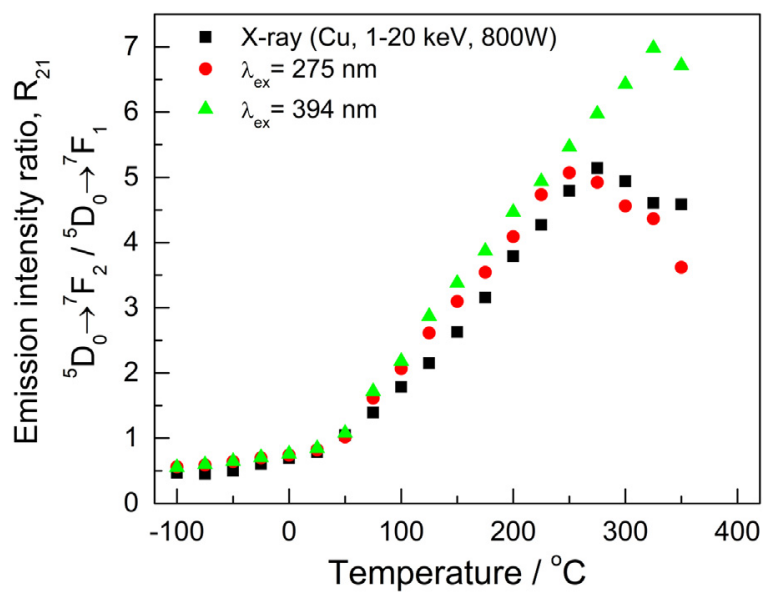

Fig. 5. $\mathrm{R}_{21}$ parameter as a function of the temperature. The parameters were obtained from emission spectra recorded under different excitations.

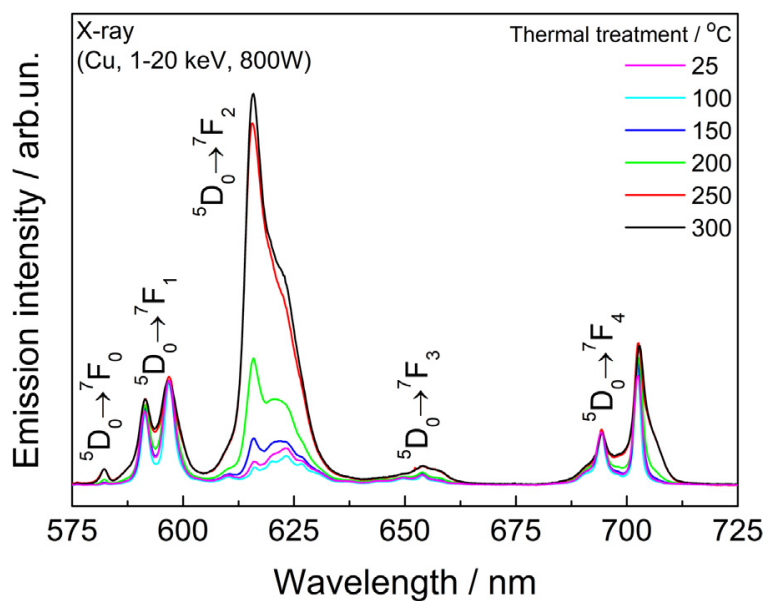

Fig. 6. X-ray excited luminescence spectra of the $\mathrm{Na}_{9}\left[\mathrm{Eu}\left(\mathrm{W}_{5} \mathrm{O}_{18}\right)_{2}\right] \cdot 14 \mathrm{H}_{2} \mathrm{O}$ sample after thermal treatment at different temperatures, recorded at $298 \mathrm{~K}$ after sample cooling. 
values decrease, probably due to the reorganization of the solid structure after water molecules leaving, which increases the $\mathrm{Eu}^{3+}$ local symmetry.

Fig. 6 shows the emission spectra of the $\mathrm{Na}_{9}\left[\mathrm{Eu}\left(\mathrm{W}_{5} \mathrm{O}_{18}\right)_{2}\right] \cdot 14 \mathrm{H}_{2} \mathrm{O}$ sample after thermal treatment at different temperatures, all recorded at $298 \mathrm{~K}$ after sample cooling. The spectra were normalized by intensity of the ${ }^{5} \mathrm{D}_{0} \rightarrow{ }^{7} \mathrm{~F}_{1}$ line. Emission spectral profile of the sample treated at $100{ }^{\circ} \mathrm{C}$ is similar to that observed for the sample without thermal treatment $\left(25^{\circ} \mathrm{C}\right)$. Structural changes promoted by heating until this temperature are only due to reticular vibrational contribution. Therefore, these structural changes until $100{ }^{\circ} \mathrm{C}$, which change the emission spectral profile as observed in Fig. 4, are reversible when the temperature of the sample decreases. Above $100{ }^{\circ} \mathrm{C}$, the dehydration process promotes significative structural changes due to water molecules leaving from solid structure, decreasing the $\mathrm{Eu}^{3+}$ local symmetry. Therefore, the intensity of the ${ }^{5} \mathrm{D}_{0} \rightarrow{ }^{7} \mathrm{~F}_{2}$ line increases in relation to ${ }^{5} \mathrm{D}_{0} \rightarrow{ }^{7} \mathrm{~F}_{1}$ line. These changes are not reversible and consequently, samples treated above $100^{\circ} \mathrm{C}$ present emission spectral profile different from that observed for the sample without thermal treatment.

\section{Conclusion}

The $\mathrm{Na}_{9}\left[\mathrm{Eu}\left(\mathrm{W}_{5} \mathrm{O}_{18}\right)_{2}\right] \cdot 14 \mathrm{H}_{2} \mathrm{O}$ sample exhibits high emission intensity under X-ray excitation, even considering the intensity decreasing due to the ionizing radiation exposure time. LMCT states are important on the scintillation mechanism of this polyoxometalate. Xray exposure along time measurements reveals that reversible electronic defects are created in the material and the emission intensity depends of the X-ray dose received and to the kinetics of generation and restitution of these defects. Finally, a possibility of application is based on the use of this material as luminescent molecular thermometer, since the $R_{21}$ parameter can be used to determine the temperature of the material in two ranges: -100 to $0^{\circ} \mathrm{C}$ and 50 to $250{ }^{\circ} \mathrm{C}$.

\section{Acknowledgments}

The authors are grateful to FAPESP, CNPq and CAPES (Brazilian Agencies) for financial support. This work was developed under institutional infrastructure support financed by FAPESP, CAPES and $\mathrm{CNPq}$ (Brazilian Agencies), as well as from CNPq grant number 475512/2009-0 and FAPESP grant number 2007/55332-7.

\section{References}

[1] P. Lecoq, A. Annenkov, A. Gektin, A., M. Korzhik, C. Pedrini, Scintillation and Inorganic Scintillators. In:___. Inorganic Scintillators for Detectors Systems: Physical Principles and Crystal Engineering. Chap. 1, Springer Verlag, New York, 2006, pp. 1-34.

[2] A. Peurrung, Mater. Today 11 (2008) 50-54.

[3] C. Greskovich, S. Duclos, Ceramic scintillators, Annu. Rev. Mater. Sci. 27 (1997) 69-88.

[4] C.W.E. van Eijk, Inorganic-scintillator development, Nucl. Instrum. Methods Phys. Res. Sect. A 460 (2001) 1-14.

[5] S.E. Derenzo, The quest for the ideal inorganic scintillator, Nucl. Instrum. Methods Phys. Res. Sect. A 505 (2003) 111-117.

[6] M.J. Weber, Inorganic scintillators: today and tomorrow, J. Lumin. 100 (2002) $35-45$.

[7] M. Nikl, Scintillation detectors for X-rays, Meas. Sci. Technol. 17 (2006) R37-R54.

[8] T. Yanagida, Opt. Mater. 35 (2013) 1987-1992.

[9] D.-L. Long, R. Tsunashima, L. Cronin, Polyoxometalates: building blocks for functional nanoscale systems, Angew. Chem. Int. Ed. 49 (2010) 1736-1758.

[10] S.Q. Liu, Z.Y. Tang, Polyoxometalate-based functional nanostructured films: current progress and future prospects, Nano Today 5 (2010) 267-281.

[11] Y.F. Song, D.L. Long, C. Ritchie, L. Cronin, Nanoscale polyoxometalate-based.

[12] E. Coronado, C.J. Gómez-García, Polyoxometalate-based molecular materials, Chem. Rev. 98 (1998) 273-296.

[13] W.G. Klemperer, C.G. Wall, Polyoxoanion chemistry moves toward the future: from solids and solutions to surfaces, Chem. Rev. 98 (1998) 297-306.

[14] D.L. Long, L. Cronin, Towards polyoxometalate: integrated nanosystems, Chem. Eur. J. 12 (2006) 3699-3706.

[15] T. Ito, T. Yamase, Molecular luminescence spectroscopy of decatungstoeuropate Langmuir-Blodgett monolayers, J. Alloy. Compd. 408-412 (2006) 813-815.

[16] R.D. Peacock, T.J.R. Weakley, Heteropolytungstate complexes of the lanthanide elements: Part I - preparation and reactions, J. Chem. Soc. A: Inorg., Phys. Theor. 1 (1971) 1836-1839.

[17] M. Sugeta, T. Yamase, Crystal structure and luminescence site of $\mathrm{Na}_{9}\left[\mathrm{EuW}_{10} \mathrm{O}_{36}\right] \cdot 32 \mathrm{H}_{2} \mathrm{O}$, Bull. Chem. Soc. Jpn. 66 (1993) 444-449.

[18] R.A.S. Ferreira, S.S. Nobre, C.M. Granadeiro, H.I.S. Nogueira, L.D. Carlos, O.L. Malta, A theoretical interpretation of the abnormal ${ }^{5} \mathrm{D}_{0} \rightarrow{ }^{7} \mathrm{~F}_{4}$ intensity based on the $\mathrm{Eu}^{3+}$ local coordination in the $\mathrm{Na}_{9} \mathrm{EuW}_{10} \mathrm{O}_{36} \cdot 14 \mathrm{H}_{2} \mathrm{O}$ polyoxometalate, J. Lumin. 121 (2006) 561-567.

[19] M.A. Cebim, H.H.S. Oliveira, N. Barelli, M.R. Davolos, Sistema para realização de medidas de luminescência com excitação por raios X, Quím. Nova 34 (2011) 1057-1062.

[20] K. Binnemans, Interpretation of europium(III) spectra, Coord. Chem. Rev. 295 (2015) 1-45.

[21] C.D.S. Brites, P.P. Lima, N.J.O. Silva, A. Millan, V.S. Amaral, F. Palacio, L.D. Carlos, Lanthanide-based luminescent molecular thermometers, New J. Chem. 35 (2011) 1177-1183.

[22] S. Uchiyama, A.P. Silva, K. Iwai, Luminescent molecular thermometers, J. Chem. Educ. 83 (2006) 720-727. 